\title{
Guidelines in Gastroenterology: Careful Interpretation Is Essential
}

\author{
Catarina Correia ${ }^{a}$ Nuno Almeida ${ }^{a, b}$ Pedro Narra Figueiredo ${ }^{a, b}$ \\ a Gastroenterology Department, Coimbra University Hospital Centre, Coimbra, Portugal; ${ }^{b}$ Faculty of Medicine, \\ University of Coimbra, Coimbra, Portugal
}

\section{Keywords}

Guidelines · Recommendations · Gastroenterology ·

Evidence level

\section{Abstract}

Introduction: Clinical practice guidelines (CPG) contain recommendations that aim to guide physicians in the diagnosis of and therapeutic approach toward patients affected by gastrointestinal (GI) pathologies. These CPG systematically combine scientific evidence and clinical judgment, culminating in recommendations that have been shown to improve patient care. Material and Methods: European and North American guidelines published in the area of gastroenterology in 2018 and 2019 were considered for inclusion. To standardize the results, only guidelines that used GRADE as an evidence system were included. Thus, in the end, 1,233 recommendations from 29 guidelines published between 2018 and 2019 were analyzed. Results: Of the 1,233 recommendations collected, 324 (26.3\%) had a low level of evidence and 127 (10.3\%) had a very low level of evidence, indicating little evidence or expert opinion. Of the 29 publications analyzed, 14 (48.3\%) did not present any recommendation with a high level of evidence. Regarding the 1,233 individual recommendations expressed in these 29 publications, only $336(27.25 \%)$ assumed a high level of evidence, with 277 (82.44\%) referring to liver pathology. Of the recommendations evaluated, 77 were from North American societies and the remaining 1,156 were European recommendations. In relation to the first group, only 3 (3.9\%) had a high level of evidence belonging to the Guidelines for Sedation and Anesthesia in GI Endoscopy. Conclusions: More than $25 \%$ of all recommendations currently accepted to guide patients with gastroenterological disorders are based on low-quality evidence or expert opinion. Thus, these documents should guide our performance, but clinical sense and multidisciplinarity must not be overlooked in dubious cases and with weak scientific evidence. Research should focus on the development of randomized controlled trials and systematic reviews to improve the evidence supporting the guidelines that guide clinical practice.

(c) 2021 Sociedade Portuguesa de Gastrenterologia Published by S. Karger AG, Basel

\section{Guidelines em Gastrenterologia - uma interpretação cuidadosa é fundamental \\ Palavras Chave \\ Diretrizes · Recomendações · Gastrenterologia · Nível de evidência}

(C) 2021 Sociedade Portuguesa de Gastrenterologia Published by S. Karger AG, Basel

This is an Open Access article licensed under the Creative Commons Attribution-NonCommercial-4.0 International License (CC BY-NC) (http://www.karger.com/Services/OpenAccessLicense), applicable to the online version of the article only. Usage and distribution for commercial purposes requires written permission.
Correspondence to:

Catarina Correia, catarina-jac@hotmail.com 


\section{Resumo}

Introdução: As diretrizes que orientam a prática clínica contêm recomendações de forma a que os médicos possam determinar os cuidados mais adequados para cada paciente. Estas diretrizes combinam evidências científicas com o julgamento clínico, culminando em recomendações destinadas a otimizar a prestação de cuidados. Material e Métodos: Diretrizes publicadas na área de Gastroenterologia entre 2018 e 2019 foram consideradas para inclusão. Para padronizar os resultados, apenas diretrizes usando o GRADE como um sistema de evidência foram incluídas. Assim, foram analisadas 1,233 recomendações de 29 diretrizes publicadas entre 2018-2019. Resultados: Das 1,233 recomendações incluídas, 334 (26.3\%) apresentavam um nível de evidência baixo e 127 (10.3\%) um nível de evidência muito baixo, indicando pouca evidência ou mesmo opinião de especialistas. Das 29 publicações analisadas, 14 (48,3\%) não apresentavam nenhuma recomendação com alto nível de evidência. Em relação às 1,233 recomendações incluídas nas 29 publicações, apenas $336(27.25 \%)$ assumiam alto nível de evidência, sendo 277 (82.44\%) referentes à patologia hepática. Das recomendações avaliadas, 77 eram de sociedades norteamericanas e as restantes 1,156 recomendações europeias. Em relação ao primeiro grupo, apenas 3 (3,9\%) possuíam alto nível de evidência e pertenciam às "Diretrizes para sedação e anestesia em endoscopia gastrointestinal." Conclusões: Mais de $25 \%$ de todas as recomendações atualmente aceites para orientar pacientes com patologias gastrointestinais são baseadas em evidências de baixa qualidade ou opinião de especialistas. Estes documentos devem orientar a nossa forma de atuar, mas o senso clínico e a abordagem multidisciplinar não devem ser esquecidos em casos duvidosos e com evidência científica fraca. A investigação deve concentrar-se no desenvolvimento de ensaios clínicos randomizados e revisões sistemáticas para melhorar as evidências que apoiam as diretrizes que orientam a prática clínica.

(c) 2021 Sociedade Portuguesa de Gastrenterologia Publicado por S. Karger AG, Basel

\section{Introduction}

It is estimated that $30 \%$ of the European population is affected, at least once in their lives, by gastrointestinal (GI) diseases [1]. Among the most prevalent pathologies in the Portuguese population, we highlight Helicobacter pylori infection (60-84\%), dyspepsia (20-40\%), gastroesophageal reflux disease (35\%), and irritable bowel syn- drome (estimated to affect between 500,000 and 1 million Portuguese) $[1,2]$. Symptoms may be harmless or can result from more serious conditions, such as inflammatory bowel disease (IBD) or GI tumors. IBD is thought to affect 15,000-20,000 people, most of them young and active individuals [1]. GI tumors are responsible for approximately $10 \%$ of deaths in Portugal. Colorectal cancer (CRC) is one of the most common cancers, and in 2020 it had a prevalence of $17.4 \%$ and a mortality rate of $14.2 \%$ in the Portuguese population [3].

Multiple GI societies have been developing many clinical practice guidelines (CPG) to guide physicians in the diagnosis of and therapeutic approach toward patients with GI diseases. These CPG systematically combine scientific evidence and clinical judgment, culminating in recommendations that have been shown to improve patient care $[4,5]$. The use of CPG is far-reaching, i.e., assisting in clinical decisions, furthering education, assessing the quality of care, guiding resource allocation, and prioritizing research [6].

There are different methodologies to classify the strength of evidence for a particular recommendation, but the GRADE (Grading of Recommendations Assessment, Development and Evaluation) system is one of the most accepted and used in international CPG [7]. Compared to other systems used to classify evidence, GRADE is the most comprehensive, considering a wider range of information [8]. GRADE is a system developed to classify the quality of evidence and the strength of health recommendations, assigning levels of evidence and classifying the robustness of recommendations for health issues. The level of evidence represents the confidence in the information that is used for that purpose. This approach provides a universal and comprehensive system for rating the quality of evidence, which is increasingly being adopted worldwide. In addition, it allows physicians and patients a way to quickly and confidently assess the quality behind recommendations. With the increasing number of CPG, systematic reviews, and randomized controlled trials (RCT), it is reasonable to assume that CPG recommendations would be based on a greater degree of high-quality evidence [9]. Unfortunately, as has been shown in studies related to other specialties, this is often not true $[10,11]$. There have been no studies surveying the quality of evidence in the gastroenterology guidelines behind different GI societies. Therein lies the rationale for our investigation: examine the proportion of high-, moderate-, low- and very-low-quality evidence to draw conclusions about the availability of evidence to gastroenter- 
Table 1. GRADE methodology levels for rating the quality of evidence

\begin{tabular}{ll}
\hline Quality level & Definition \\
\hline High & $\begin{array}{l}\text { One or more updated, high-quality systematic } \\
\text { reviews that are based on at least } 2 \text { high-quality } \\
\text { primary studies with consistent results }\end{array}$ \\
\hline Moderate & $\begin{array}{l}\text { Moderate effect: the true effect is likely close to } \\
\text { the estimate of the effect but may be substantial- } \\
\text { ly different }\end{array}$ \\
\hline Low & $\begin{array}{l}\text { Limited confidence: the true effect may be sub- } \\
\text { stantially different from the estimate of the ef- } \\
\text { fect }\end{array}$ \\
\hline Very low & $\begin{array}{l}\text { Little confidence: the true effect is likely sub- } \\
\text { stantially different from the estimate of the ef- } \\
\text { fect }\end{array}$ \\
\hline
\end{tabular}

ologists. Therefore, the aim of this research was to review the guidelines published by some of the most relevant GI societies between 2018 and 2019. Our goal was to report the level of evidence supporting their recommendations and to identify areas where evidence can be improved with additional research.

\section{Materials and Methods}

A list of CPG published between 2018 and 2019, in the gastroenterology area, were obtained by searching the websites from some of the international societies that follow our daily clinical practice. European CPG were obtained from the United European Gastroenterology (UEG) database [12]. American CPG data were collected from the American Gastroenterological Association (AGA), the American College of Gastroenterology (ACG), the American Association for the Study of Liver Diseases (ASSLD), and the American Society for Gastrointestinal Endoscopy (ASGE) [13-16]. A total of 89 European and North American CPG published in the gastroenterology field between 2018 and 2019 were analyzed. In order to standardize the collected sample, CPG that did not use the GRADE system to rate the quality of evidence and CPG that were still in execution or ones without levels of evidence for their recommendations were excluded. Considering this, only 29 guidelines were considered for inclusion. This proportion of CPG analyzed and included in the study is shown in Figure 1. All of the guidelines included in the research are presented in online supplementary material (for all online suppl. material, see www. karger.com/doi/10.1159/000518322).

The quality of the evidence is classified into the following 4 levels: high, moderate, low, and very low (Table 1) [7]. A total of 1,233 recommendations from the 29 guidelines were analyzed. Afterwards, all 1,233 recommendations were extracted into an SPSS spreadsheet with its associated level of evidence. We also stratified

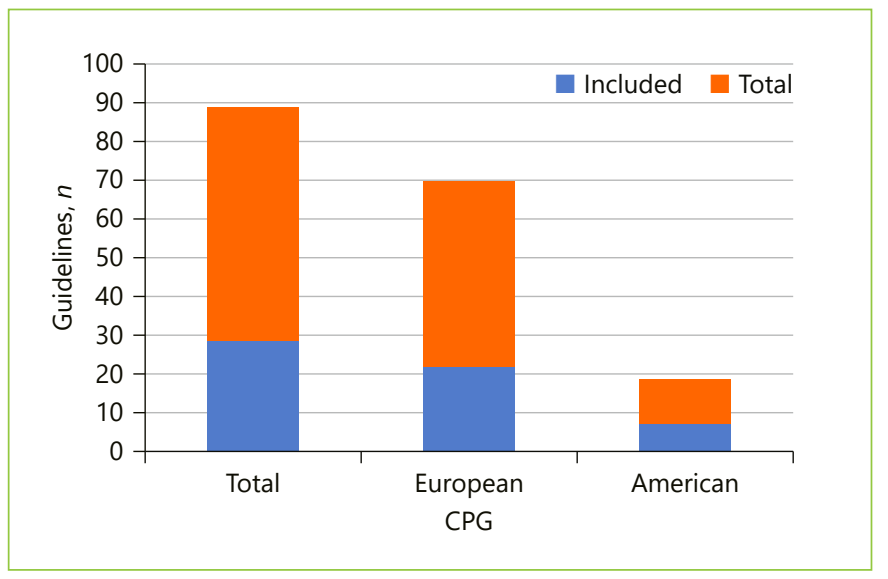

Fig. 1. Representation of the proportion of total CPG analyzed and included in this study.

the list by the guideline in which they were published along with the year of publication.

The statistical analysis was performed using statistical software (SPSS version 23). Frequencies and proportions were calculated to describe the collected data.

\section{Results}

A total of 29 guidelines ( 7 from American societies and 22 from European societies) were included in this study, representing 1,233 recommendations. Of the 1,233 recommendations collected, $324(26.3 \%)$ were based on a low level of evidence and $127(10.3 \%)$ were based on a very low level of evidence, indicating poor evidence or expert opinion. Four hundred forty-six (36.2\%) were based on a moderate level of evidence and 336 (27.3\%) were based on high levels of evidence, with 277 (82.44\%) of these being related to liver disease. These results are detailed in Table 2.

Only 2 guidelines - the European Association for the Study of the Liver (EASL) Recommendations on Treatment of Hepatitis C (2018) [17] and the EASL Clinical Practice Guidelines: Management of Alcohol-Related Liver Disease [18] - had over $50 \%$ of recommendations supported by high-level evidence.

Of the 29 publications analyzed, 14 (48.3\%) did not present any recommendation with a high level of evidence, 15 contained high-level recommendations, and only $2(6.7 \%)$ did not present recommendations with a low or very low level of evidence (Fig. 2). 
Table 2. Analysis of recommendations included in this study by society, field of gastroenterology, and proportion of evidence levels for each society

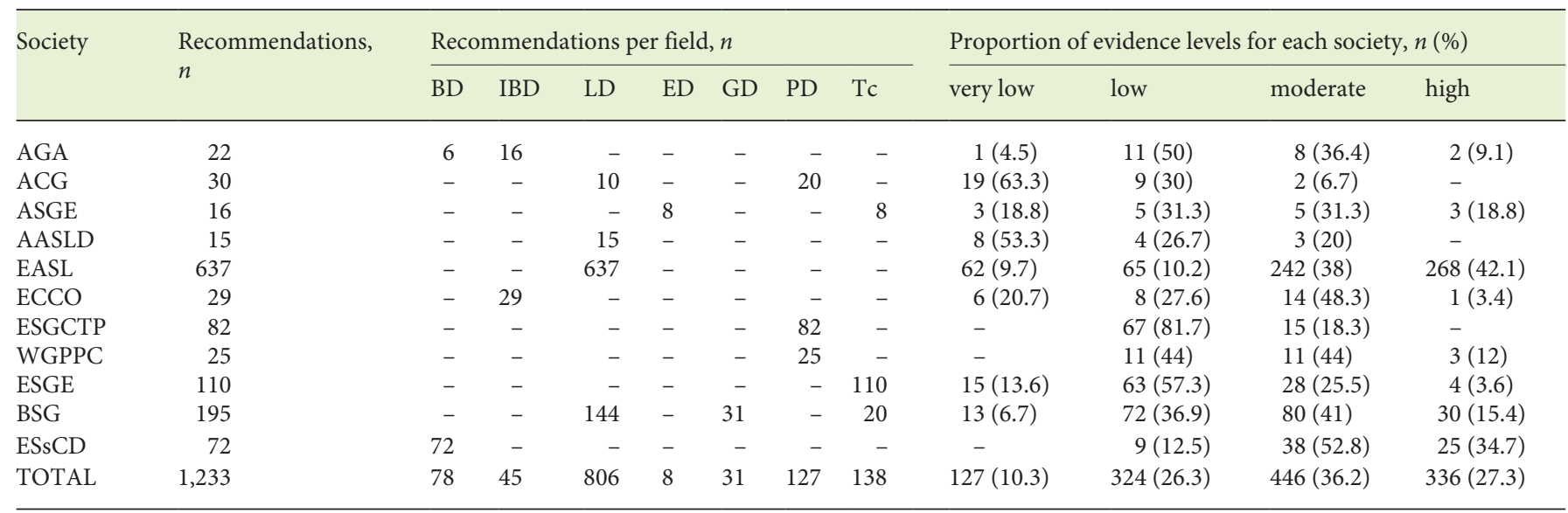

ECCO, European Crohn's and Colitis Organization; ESGCTP, European Study Group on Cystic Tumors of the Pancreas; WGPPC, Working Group of the Polish Pancreatic Club; BSG, British Society of Gastroenterology; ESsCD, European Society for the Study of Coeliac Disease; BD, bowel disease (not IBD); $\mathrm{LD}$, liver disease; ED, esophageal disease; GD, gastric disease; PD, pancreatic disease; Tc, techniques in gastrointestinal endoscopy.

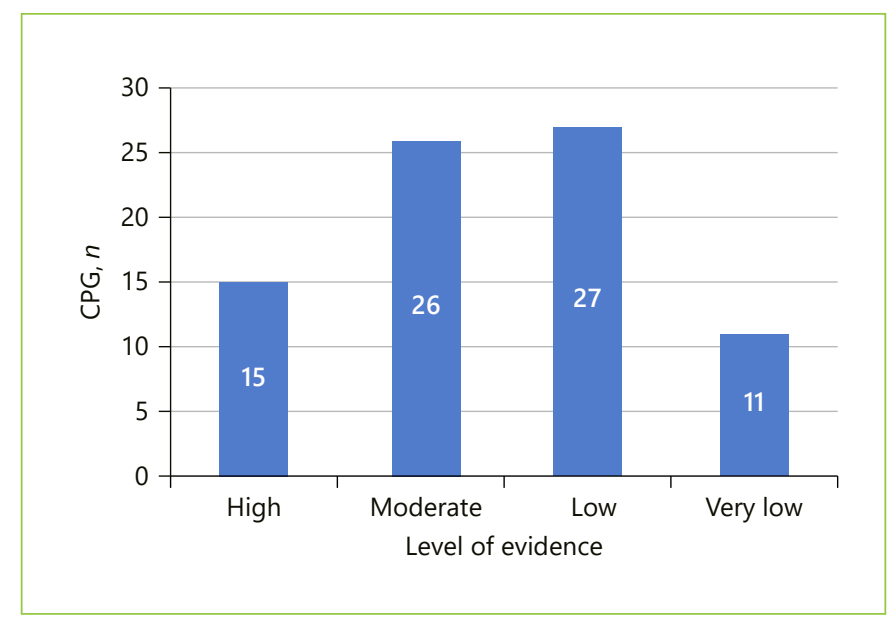

Fig. 2. Representative number of CPG which contain recommendations with the different levels of evidence.

Of the recommendations evaluated, 77 were from North American societies and the remaining 1,156 were European recommendations. In relation to the first group, only 3 (3.9\%) had a high level of evidence, belonging to the same guideline - Guidelines for Sedation and Anesthesia in GI Endoscopy. The analysis of recommendations per field showed that only the ones related to liver and bowel diseases (not IBD) had a proportion with a high level of evidence higher than 30\% (34.37 and 33.3\%,
Table 3. Proportion of high-level evidence per field of gastroenterology

\begin{tabular}{lc}
\hline Field of gastroenterology & $\begin{array}{l}\text { Proportion of } \\
\text { recommendations } \\
\text { of high-level } \\
\text { evidence }\end{array}$ \\
\hline Liver disease & $277 / 806(34.37)$ \\
Bowel disease (not IBD) & $26 / 78(33.3)$ \\
Esophageal disease & $18 / 100(18)$ \\
Gastric disease & $3 / 31(9.68)$ \\
Techniques in gastrointestinal endoscopy & $7 / 138(5.07)$ \\
IBD & $2 / 45(4.44)$ \\
Pancreatic disease & $3 / 127(2.36)$ \\
Total & $336 / 1,233(27.25)$ \\
\hline
\end{tabular}

Values in parentheses are percents. respectively). Table 3 reports the proportion of recommendations with high-level evidence per "field" of gastroenterology.

The year 2018 had the highest percentage of recommendations supported by a high level of evidence $(88.7 \%$, 298 out of 336). Between 2018 and 2019, the percentage of recommendations supported by a low level of evidence increased from 20.8 to $37.3 \%$. 
In this research we only included guidelines published in

The 29 guidelines analyzed contained 1,233 recommendations. More than a quarter $(26.3 \%)$ were based on a low evidence level and only $27.3 \%$ were supported by high evidence levels.

A similar study performed by the American College of Emergency Physicians found that less than $10 \%$ of their recommendations were based on high-quality evidence, and the majority were based on expert opinion [19]. Similarly, the American College of Chest Physicians found that only $0.4 \%$ of recommendations for the treatment of thromboembolism were based on high-level evidence [20]. In the field of gastroenterology, a similar study done by Meyer et al. [21], analyzing the scientific evidence underlying the American College of Gastroenterology (ACG) CPG also concluded that very few recommendations made by the AGA are supported by high levels of evidence. More than half of all recommendations made by the AGA are based on low-quality evidence or expert opinion [21]. Feuerstein et al. [22] also referred that when the gastroenterology guidelines rate the quality of evidence for their recommendations most recommendations are based on lower-quality evidence. A systematic analysis and critical appraisal of the quality of the scientific evidence in Practice Guidelines for Barrett's Esophagus revealed that nearly $50 \%$ of the recommendations are based on expert opinion or poor-quality evidence [23]. A critical review of scientific evidence and evolving recommendations of AASLD CPG also concluded that, despite significant increases in the numbers of recommendations within AASLD practice guidelines over time, only a minority are supported by grade I evidence, highlighting the need for developing well-designed investigations to provide evidence for areas of uncertainty and improving the quality of future guidelines in hepatobiliary diseases [24].

Although the amount of high-level evidence supporting the CPG included in our study (26.3\%) compares favorably to the previously mentioned papers, this is far from what would be expected. When considering the proportion of recommendations with a high level of evidence demonstrated in Tables 2 and 3, it is notable that these low percentages of recommendations with a high level of evidence will affect the overall quality of the guidelines reported. These results confirm that, although guidelines should be followed, interpretation with caution and careful clinical judgment is mandatory.

A limitation of our study was the impossibility to analyze how evidence levels can differ from recommendations related with the same topic in different guidelines.
2018 and 2019, and consequently the topics covered are pretty much all different, even within the same area (online suppl. material). Considering this limitation of our research, the only 2 guidelines which address the same topic are the ACG Clinical Guideline: Diagnosis and Management of Pancreatic Cysts and European evidence-based guidelines on pancreatic cystic neoplasms $[25,26]$. In this case, there were no big discrepancies between them - they were published in the same year (2018) and addressed the same topic. In both, there were no recommendations with a high level of evidence. Regarding recommendations with a low and very low level of evidence, the American guideline and the European guideline presented a proportion of 100 and $81.7 \%$, respectively.

RCT are the cornerstone of clinical decision making, and the field of gastroenterology has a poor history of producing influential RCT [27]. Nearly 25,000 RCT are published each year but, given that 14 of the analyzed guidelines do not contain recommendations with a high level of evidence, it appears that few RCT find their way into CPG in the field of gastroenterology [28].

The discrepancy between the total number of gastroenterology RCT and those supporting guideline recommendations may be due to 2 factors: overlap between RCT and practical barriers to conducting RCT. The potential overlap between RCT, also known as research waste, may delay the advent of treatments for patients with preventable diseases $[29,30]$. For example, in our study we found that, of the 14 guidelines with no highquality evidence, almost all were focused on either prevention, treatment, or management. While some of these individual recommendations may not be subjectable to an RCT due to ethical or practical concerns, some of these may be tested in a randomized fashion.

Koh et al. [24] reported a 36\% increase in recommendation number for the AASLD since their development in 1998. Nonetheless, despite this substantial increase, less than $15 \%$ were based on high-grade evidence. Since 2003, the National Institutes of Health budget for digestive disease research reached a plateau, while corporate funding for gastroenterology research dropped by more than $60 \%$ since 2008 [31, 32]. This translates into increased competition for grant applications, which are being awarded at the lowest rate in decades [33]. RCT are among the most time-consuming and expensive research studies, despite producing the highest level of evidence. We suggest that the multiple gastroenterology organizations should encourage future research to strengthen rec- 
ommendations that are currently supported by expert opinion or a low evidence level.

Some studies have estimated that $54-70 \%$ of physicians consistently use CPG in practice, so their quality is of the greatest importance $[5,34]$. Therefore, the scarcity of high-quality evidence affects physicians seeking evidence-based treatment options and patients seeking evidence-based care. Recommendations that are based on low levels of evidence are important areas for research as they may expose patients to unnecessary risks and inflate health care costs [35]. CPG can give physicians a false sense of security, causing them to rely more on the guideline than on critical-thinking and updated research [28]. This shows the importance of basing guideline recommendations on high-level evidence. When creating guidelines from expert consensus they are subject to bias. Conflicts of interest are potential sources of bias in the development of CPG [36]. Another major problem in basing recommendations on expert consensus is the fact that opinions vary between experts. This is illustrated in a study where Marras et al. [37] found the highest percent of expert agreement on any recommendation was $81 \%$. Without further evidence validating one opinion over another, physicians will use their judgment to treat patients, leading to variability in care. The number of gastroenterology recommendations supported by low-level evidence and expert opinion highlights the need for further research leading to better evidence and improved patient outcomes.

\section{Limitations}

A limitation of our study is the use of guideline repositories, which are disposed to more variations than public databases. The reduce number of guidelines and recommendations included, in some fields, should lead to careful interpretation of results.

Because the guidelines were published before the current year, they may not be an accurate reflection of the current levels of evidence in gastroenterology literature and therefore our study may underestimate the current research quality in the field.

\section{Conclusion}

More than a quarter of all recommendations are based on low-quality evidence or expert opinion. Considering the CPG included, 14 of the 29 CPG that guide our practice do not contain recommendations supported by highlevel evidence. All CPG recommendations should be considered equally relevant. The recommendations contain supporting evidence ranging from high quality (RCT) to low quality (expert opinion). Research should focus on the development of RCT and systematic reviews to improve the evidence supporting the CPG that guide our daily practice.

\section{Statement of Ethics}

All of the procedures performed were in accordance with the ethical standards of the institutional and/or national research committee.

\section{Conflict of Interest Statement}

The authors have no conflict of interests to declare.

\section{Funding Sources}

The authors received no financial support.

\section{Author Contributions}

The authors contributed equally to the writing of this paper.

\section{References}

1 de Carvalho IM, NunesS, de Matos L, et al. Gastrenterologia e Hepatologia. Rede Nacional de Especialidade Hospitalar e de Referenciação. 2017.

2 Bastos J, Peleteiro B, Barros R, Alves L, Severo $M$, de Fátima Pina M, et al. Sociodemographic determinants of prevalence and incidence of Helicobacter pylori infection in Portuguese adults. Helicobacter. 2013 Dec;18(6):413-22.

3 World Health Organization. The Global Cancer Observatory - Portugal. 2020 [cited 2021
Apr 4]. Available from: https://gco.iarc.fr/to$\mathrm{day} / \mathrm{data} / \mathrm{factsheets/populations/620-portu-}$ gal-fact-sheets.pdf.

4 Graham R, Mancher M, Miller Wolman D, et al. Clinical practice guidelines we can trust. Washington: National Academies Press; 2011.

5 Palareti G, Legnani C, Cosmi B, Antonucci E, Erba N, Poli D, et al.; DULCIS (D-dimerULtrasonography in Combination Italian Study) Investigators (See Appendix);
DULCIS (D-dimer-ULtrasonography in Combination Italian Study) Investigators. Comparison between different D-Dimer cutoff values to assess the individual risk of recurrent venous thromboembolism: analysis of results obtained in the DULCIS study. Int J Lab Hematol. 2016 Feb;38(1):429.

6 Clinical Practice Guidelines. 2005. Available from: http://www.library.tmc.edu/pracguid. html. 
7 Kavanagh BP. The GRADE system for rating clinical guidelines. PLoS Med. 2009 Sep;6(9):e1000094.

8 Ministério da Saúde. Diretrizes metodológicas: Sistema GRADE - Manual de graduação da qualidade da evidência e força de recomendação para tomada de decisão em saúde. Brasilia: Ministério da Saúde: 2014.

9 Booth A, Clarke M, Ghersi D, Moher D, Petticrew M, Stewart L. An international registry of systematic-review protocols. Lancet. 2011 Jan;377(9760):108-9.

10 Wright JD, Pawar N, Gonzalez JS, Lewin SN, Burke WM, Simpson LL, et al. Scientific evidence underlying the American College of Obstetricians and Gynecologists' practice bulletins. Obstet Gynecol. 2011 Sep;118(3): 505-12.

11 Tricoci P, Allen JM, Kramer JM, Califf RM, Smith SC Jr. Scientific evidence underlying the ACC/AHA clinical practice guidelines. JAMA. 2009 Feb;301(8):831-41.

12 United European Gastroenterology. Standards and guidelines. 2021 [cited 2021 Apr 4]. Available from: https://ueg.eu/library\#stq=* \&stp $=1 \&$ sts $=$ Default\&stc $=$ All\&stcf $=$ All\&stf $=$ Standards and Guidelines\&stms $=\mathrm{All} \& \mathrm{sty}=\mathrm{Al}$ l\&reload.

13 American Society for Gastrointestinal Endoscopy. Guidelines. 2021 [cited 2021 Apr 4]. Available from: https://www.asge.org/home/ guidelines.

14 American Association for the Study of Liver Diseases. Practice guidelines. 2021 [cited 2021 Apr 4]. Available from: https://www.aasld. org/publications/practice-guidelines.

15 American Gastroenterological Association. Clinical guidelines. 2021 [cited 2021 Apr 4] Available from: https://gastro.org/guidelines/.

16 American College of Gastroenterology. Guidelines. 2021 [cited 2021 Apr 4]. Available from: https://gi.org/guidelines/.

17 Pawlotsky JM, Negro F, Aghemo A, Berenguer M, Dalgard O, Dusheiko G, et al.; European Association for the Study of the Liver. Electronic address: easloffice@easloffice.eu; European Association for the Study of the Liver. EASL Recommendations on Treatment of Hepatitis C 2018. J Hepatol. 2018 Aug; 69(2):461-511.
18 Thursz M, Gual A, Lackner C, Mathurin P, Moreno C, Spahr L, et al.; European Association for the Study of the Liver. Electronic address: easloffice@easloffice.eu; European Association for the Study of the Liver. EASL Clinical Practice Guidelines: management of alcohol-related liver disease. J Hepatol. 2018 Jul;69(1):154-81.

19 Venkatesh AK, Savage D, Sandefur B, Bernard KR, Rothenberg C, Schuur JD. Systematic review of emergency medicine clinical practice guidelines: implications for research and policy. PLoS One. 2017 Jun;12(6): e0178456.

20 Shah S, Khan AR, Khan S, Assaly R. Evidence Underlying the American College of Chest Physicians (ACCP) Clinical Practice Guidelines for the Prevention, Diagnosis, and Management of Venous Thromboembolism. Chest. 2014;146(4):821A.

21 Meyer C, Bowers A, Wayant C, Checketts J, Scott J, Musuvathy S, et al. Scientific evidence underlying the American College of Gastroenterology's clinical practice guidelines. PLoS One. 2018 Oct;13(10):e0204720.

22 Feuerstein JD, Gifford AE, Akbari M, Goldman J, Leffler DA, Sheth SG, et al. Systematic analysis underlying the quality of the scientific evidence and conflicts of interest in gastroenterology practice guidelines. Am J Gastroenterol. 2013 Nov;108(11):1686-93.

23 Feuerstein JD, Castillo NE, Akbari M, Belkin E, Lewandowski JJ, Hurley CM, et al. Systematic Analysis and Critical Appraisal of the Quality of the Scientific Evidence and Conflicts of Interest in Practice Guidelines (20052013) for Barrett's Esophagus. Dig Dis Sci. 2016 Oct;61(10):2812-22.

24 Koh C, Zhao X, Samala N, Sakiani S, Liang TJ, Talwalkar JA. AASLD clinical practice guidelines: a critical review of scientific evidence and evolving recommendations. Hepatology. 2013 Dec;58(6):2142-52.

25 Elta GH, Enestvedt BK, Sauer BG, Lennon AM. ACG Clinical Guideline: Diagnosis and Management of Pancreatic Cysts. Am J Gastroenterol. 2018 Apr;113(4):464-79.

26 Del Chiaro M, Besselink MG, Scholten L, Bruno MJ, Cahen DL, Gress TM, et al.; European Study Group on Cystic Tumours of the Pancreas. European evidence-based guidelines on pancreatic cystic neoplasms. Gut. 2018 May; 67(5):789-804.
27 Elmunzer BJ. Increasing the Impact of Randomized, Controlled Trials in Gastrointestinal Endoscopy. Gastroenterology. 2015 Sep;149(3):521-5.

28 Heath I. Who's complacent now? The King's Fund on general Practice: the King's Fund report into general practice fudges important issues. BMJ. 2011. doi: 10.1136/bmj.d225.

29 Ioannidis PA, Greenland S, Hlatky MA, Khoury MJ, Macleod MR. Research: ilncreasing value, reducing waste 2 - Increasing value and reducing waste in research design, conduct, and analysis. Lancet. 2016;383:166-75.

30 Chalmers I, Bracken MB, Djulbegovic B, Garattini S, Grant J, Gülmezoglu AM, et al. How to increase value and reduce waste when research priorities are set. Lancet. 2014 Jan;383(9912):156-65.

31 James SP. Opportunities and Challenges at NIDDK in Digestive Diseases Research. Gastroenterology. 2007 Apr;132(4):1219-20.

32 Szentesi A, Tóth E, Bálint E, Fanczal J, Madácsy T, Laczkó D, et al.; Hungarian Pancreatic Study Group. Analysis of research activity in gastroenterology: pancreatitis is in real danger. PLoS One. 2016 Oct;11(10):e0165244.

33 Yang VW. The challenges facing GI investigators today and what (more) the GI societies can do to help. Gastroenterology. 2007 Dec;133(6):1761-2.

34 Kenefick H, Lee J, Fleishman V. Improving physician adherence to clinical practice guidelines barriers and strategies for change. Boston: New Engl Healthcare Institute; 2008.

35 Unnecessary overuse of medical care causes both waste and harm. 2017. Available from: https://www.the-hospitalist.org/hospitalist/ article/122392/medical-care-overuse-causeswaste-harm-healthcare.

36 Norris SL, Holmer HK, Burda BU, Ogden LA, $\mathrm{Fu}$ R. Conflict of interest policies for organizations producing a large number of clinical practice guidelines. PLoS One. 2012;7(5): e37413.

37 Marras TK, Prevots DR, Jamieson FB, Winthrop KL; Pulmonary MAC Outcomes Group. Variable agreement among experts regarding Mycobacterium avium complex lungdisease. Respirology.2015Feb;20(2):34851. 